\title{
MP
}

\section{Expression of STK39 in peripheral blood of hypertension patients and the relationship between its genetic polymorphism and blood pressure}

\author{
B. $\mathrm{Li}^{1}$, M. Yang ${ }^{2}$ and J.W. Liu ${ }^{1}$ \\ 'Department of Cardiology II, \\ The Third Affiliated Hospital of Xinxiang Medical University, Xingxiang, China \\ 2Department of Cardiology I, \\ The Third Affiliated Hospital of Xinxiang Medical University, Xingxiang, China \\ Corresponding author: J.W. Liu \\ E-mail: jingweiliucn@126.com
}

Genet. Mol. Res. 14 (4): 16461-16468 (2015)

Received July 14, 2015

Accepted September 25, 2015

Published December 9, 2015

DOI http://dx.doi.org/10.4238/2015.December.9.17

ABSTRACT. This study investigated the STK39 expression in peripheral blood of hypertension patients and the relation between its genetic polymorphism and blood pressure. The observation group comprised of 42 primary hypertension patients admitted to our hospital, and the control group comprised of 30 healthy individuals who underwent physical examination in our hospital during the same period. Fasting venous blood was collected from both groups in the morning to determine the STK39 mRNA and protein levels in peripheral blood using quantitative real-time PCR and western blot. STK39 gene SNP (rs6433027) was sequenced using PCR and its genetic variation was analyzed. The relationship between STK39 protein level, genetic variation, and diastolic and systolic blood pressure was also analyzed. The observation group showed increased STK39 mRNA and protein levels in peripheral blood compared to the control group, and the difference was statistically significant $(P<0.05)$, suggesting $C / T$ mutation 
in STK39 gene SNP (rs6433027). Correlation analysis showed positive association between STK39 protein level and diastolic and systolic blood pressure $(P<0.05)$, indicating a positive association between $C / T$ genetic mutation and diastolic and systolic blood pressure $(P<0.05)$. In conclusion, STK39 mRNA and protein express abnormally in primary hypertension patients with genetic variation, which is related to the blood pressure.

Key words: STK39; Primary hypertension; Genetic variation; Diastolic blood pressure; Systolic blood pressure

\section{INTRODUCTION}

Hypertension is a common life-threatening cardiovascular disease that greatly affects human health and has become a public health issue requiring attention around the world. Worldwide, around $25 \%$ of adults had been diagnosed with hypertension; and the number is estimated to rise by $60 \%$ in 2025 , i.e., 1560 million people will suffer from it (Su, 2010). Primary hypertension is an independent risk factor for the development of myocardial infarction, cardiac failure, cerebrovascular diseases, and chronic renal failure. However, the cause and pathogenesis of hypertension are not yet clear. Hypertension results from the interaction of multiple genetic and environmental factors. Genetic factors affecting blood pressure account for 30 to 50\%; however, related researches on the role of gene in hypertension are rare (Keamey et al., 2005; Kato et al., 2011). Tremendous progression has been seen in the field of whole genome sequencing and restriction endonuclease length polymorphism. The advent of Genome-wide Association Study (GWAS) based on SNP chip technology has revolutionized the treatment of primary hypertension (Pan et al., 2015). Recently, the GWAS on diseases such as tumors, cardiovascular diseases, diabetes, hypertension, and schizophrenia has developed rapidly all around the world. GWAS reports on several susceptibility genes of primary hypertension in Europe, China, Japan, and South Korea lay a foundation for studying the pathogenesis of hypertension (Pearson and Manolio, 2008; Levy et al., 2009). Serinethreonine kinase 39 (STK 39) was reported to be a susceptibility gene locus for hypertension in Amish individuals. Studies showed that two common genetic variations of STK39, rs3754777, and rs6433027, are the susceptibility gene loci of hypertension in Han Chinese males (Duarte et al., 2010; Xu et al., 2013). Changes in STK39 expression in the serum of hypertension patients and the genetic variation of STK39 gene SNP (rs6433027) needs to be further explored. Hence, this study analyzes the expression and genetic variation of STK39 in primary hypertension patients, aiming to provide a theoretical basis for studying the genetic factors of hypertension.

\section{MATERIAL AND METHODS}

\section{Clinical data}

The observation group comprised of 42 primary hypertension patients, admitted into our hospital from September 2012 to September 2014. The inclusion criteria are: 1) all patients conformed to the clinical diagnosis criteria in A Guide to Chinese Hypertension Prevention and Treatment; 2) patients aged from 50 to 75 were included; 3) patients were male; 4) the patients had signed the informed consent; 5) the research was approved and supervised by Medical Ethics 
Committee of the hospital. The exclusion criteria are: 1) secondary hypertension patients; 2) patients diagnosed with coronary heart disease by coronary angiography; 3) patients with diabetes, hyperlipemia, or thrombosis; 4) patients with liver and kidney diseases, autoimmune diseases, and tumors; 5) patients who underwent surgery or were injured recently. The average age of the 42 patients was $63.12 \pm 11.36$. The control group comprised of 30 healthy individuals, aged from 50 to 76 with an average age of $62.26 \pm 12.03$, who underwent physical examination during the same period. The comparison of the indexes like age was not statistically significant $(P>0.05)$. This study was conducted in accordance with the declaration of Helsinki with the approval from the Ethics Committee of the Third Affiliated Hospital of Xinxiang Medical University. Written informed consent was obtained from all participants.

\section{Pretreatment of blood samples}

Fasting venous blood $(5 \mathrm{~mL})$ was collected from both groups in the morning. The blood sample $(2.5 \mathrm{~mL})$ was kept at room temperature for $30 \mathrm{~min}$ and then centrifuged for $5 \mathrm{~min}$ at 3000 $\mathrm{rpm} / \mathrm{min}$ and the serum was collected. The other blood sample $(2.5 \mathrm{~mL})$ was separated with density gradient centrifugation to get peripheral blood mononuclear cell (PBMC) for total RNA extraction.

\section{Quantitative real-time PCR}

TRIzol (TaKaRa, Dalian, China) $(1 \mathrm{~mL})$ was added to the obtained PBMC and then mixed by shaking. Chloroform $(200 \mu \mathrm{L})$ was then added and mixed, and placed on ice for segregation. It was then centrifuged for $15 \mathrm{~min}$ at $12,000 \mathrm{rpm} / \mathrm{min}$. Equal volume of isopropanol was added to the supernatant $(500 \mu \mathrm{L})$ and was agitated. It was placed on ice for $30 \mathrm{~min}$ and then centrifuged for 15 $\mathrm{min}$ at $15,000 \mathrm{rpm} / \mathrm{min}$. The supernatant was discarded, and the sediment was washed with precooled $70 \%$ alcohol once and centrifuged for $6 \mathrm{~min}$ at $8000 \mathrm{rpm} / \mathrm{min}$. The sediment was dissolved in double-distilled water treated by DEPC, and the RNA concentration was detected and RNA extraction mass was measured. Reverse transcription was performed on extracted RNA to obtain cDNA with a reverse transcription kit (TaKaRa) following manufacturer instructions; the obtained cDNA was taken as the template of RT-PCR.

Based on STK39 mRNA sequence, STK39 primers were designed: STK39-F1, 5'-CGGCAGTGGAGCTACTGCTG-3' and STK39-R1, 5'-CACTACGTTGGGATGGCTGC-3'. First, the specificity and annealing temperature of primers were optimized with conventional PCR. Second, the following reaction systems were prepared: $25 \mu \mathrm{L} 2 \mathrm{X}$ SYBR Green RT-PCR mix (Vazyme Biotech Co., Ltd., Nanjing, China), $1 \mu \mathrm{L}$ primers, $1 \mu \mathrm{L}$ cDNA, and enough water to make up the volume to $50 \mu \mathrm{L}$. A given volume of reactants was prepared according to the sample number, and then added into quantitative real time PCR 96-hole plate. Centrifugation at 1500 $\mathrm{rpm} / \mathrm{min}$ for $1 \mathrm{~min}$ flung the reaction liquid to the bottom of the tube. Third, the following reaction conditions were set on the RT-PCR: pre-denaturation at $95^{\circ} \mathrm{C}$ for $30 \mathrm{~s}$; denaturation at $95^{\circ} \mathrm{C}$ for 3 $\mathrm{s}$; and annealing and extension at $60^{\circ} \mathrm{C}$ for $30 \mathrm{~s}$. The results were recorded in the end $(\mathrm{ABI} 7500$; Applied Biosystems, Foster City, CA, USA).

\section{Western blot}

Peripheral blood samples were collected from the two groups. Erythrocytes in the blood samples were lysed using erythrocyte lysate. White blood cells were collected after centrifugation 
for $30 \mathrm{~min}$ and were mixed with lysate on ice and centrifuged for $5 \mathrm{~min}$ at $12,000 \mathrm{rpm} / \mathrm{min}$. The supernatant was collected and added to boiling loading buffer and boiled for $10 \mathrm{~min}$, and later SDSPAGE was performed. When the bromophenol blue was out of the lower edge of the gel, the protein was moved onto nitrocellulose (NC) membrane. After 30 min of sealing with $5 \%$ of skimmed milk powder, it was incubated with mouse anti-human STK39 monoclonal antibody (Abcam, Cambridge, UK) diluted at 1:2000 overnight. Next day, it was washed three times with phosphate-buffered saline with Tween 20 (PBST), and then incubated at $37^{\circ} \mathrm{C}$ with horseradish peroxidase (HRP)-labeled goat anti-mouse secondary antibody (ZSJQ-BIO, Beijing, China) for $1 \mathrm{~h}$, and luminescent liquid was used for development. Meanwhile, glyceraldehyde 3-phosphate dehydrogenase (GAPDH) was adopted as internal reference. The gradation of western blot bandings of STK39 and GAPDH protein was analyzed with software, and the ratio of STK39 to GAPDH banding gradation was used as the relative expression level of STK39 protein.

\section{The analysis of amplification and variation of STK39 gene SNP (rs6433027)}

Based on STK39 gene sequence, STK395-F2 and STK39-R2 were designed: STK395-F2, CAATCTTAATCTGAAGAAAGTG and STK39-R2: GTCTTATAGGACTACTCATCT. The following PCR system was prepared: $25 \mu \mathrm{L} 2 \mathrm{X}$ Taq DNA polymerase mix (TaKaRa), $1 \mu \mathrm{L}$ STK395-F2, $1 \mu \mathrm{L}$ STK39-R2, $1 \mu \mathrm{L}$ CDNA, and water was added to make up the volume to $50 \mu \mathrm{L}$. PCR was carried out according to the following reaction conditions: pre-denaturation at $94^{\circ} \mathrm{C}$ for $5 \mathrm{~min}$, denaturation at $94^{\circ} \mathrm{C}$ for $30 \mathrm{~s}$, annealing at $55^{\circ} \mathrm{C}$ for $30 \mathrm{~s}$, and extension at $72^{\circ} \mathrm{C}$ for 2 min for 30 cycles, and then the temperature was lowered to $4^{\circ} \mathrm{C}$. The PCR products were connected to T vector (TaKaRa) according to the $\mathrm{T}$ vector instruction manual. Escherichia coli DH5a (TaKaRa) was transformed and seeded on solid LB plates and cultured at $37^{\circ} \mathrm{C}$ overnight. On the next day, monoclonal colonies were selected for sequencing analysis.

\section{Statistical analysis}

All data were analyzed with SPSS 17.0 statistical software (SPSS Inc., Chicago, IL, USA). The measured data was expressed by means $\pm \mathrm{S}$, and the comparison of measured data was checked by Student $t$-test. The comparison of numeration data was checked with chi-square test; the correlation analysis was checked by Pearson's test. The difference $P<0.05$ was considered statistically significant.

\section{RESULTS}

\section{The comparison of general data}

In both groups, the comparison of indexes such as age, gender, TC, HDL-C, LDL-C, WHR, fasting blood sugar, fasting insulin was of no statistical significance $(P>0.05)$. The observation group had a higher SBP and DBP level than the control group, and the difference was statistically significant $(P<0.05)$ (Table 1$)$.

\section{Comparison of STK39 mRNA levels in peripheral blood cells}

In the experiment, quantitative real time PCR detected the level of STK39 mRNA, as 
shown in Figure 1. Quantitative analysis indicated that the observation group has a higher level of STK39 mRNA in peripheral blood cells than the control group, and the difference was statistically significant $(P<0.05)$.

Table 1. Comparison of general information in both groups.

\begin{tabular}{lccc}
\hline Items & Control group & Observation group & P value \\
\hline Sex (Male/Female) & $28 / 14$ & $17 / 13$ & 0.43 \\
Age & $63.1 \pm 11.3$ & $62.2 \pm 12.0$ & 0.79 \\
TC $(\mathrm{mM})$ & $4.03 \pm 0.49$ & $4.31 \pm 0.60$ & 0.59 \\
TG $(\mathrm{mM})$ & $1.22 \pm 0.31$ & $1.26 \pm 0.33$ & 0.78 \\
HDL-C $(\mathrm{mM})$ & $1.61 \pm 0.31$ & $1.67 \pm 0.31$ & 0.32 \\
LDL-C (mM) & $2.69 \pm 0.46$ & $2.58 \pm 0.51$ & 0.79 \\
Fasting blood sugar (mM) & $5.11 \pm 0.62$ & $5.20 \pm 0.49$ & 0.58 \\
SBP & $127.3 \pm 9.4$ & $175.3 \pm 10.5$ & $0.02^{*}$ \\
DBP & $75.9 \pm 8.5$ & $96.55 \pm 9.7$ & $0.03^{*}$ \\
\hline
\end{tabular}

${ }^{*}$ Compared with the control group, $\mathrm{P}<0.05$.

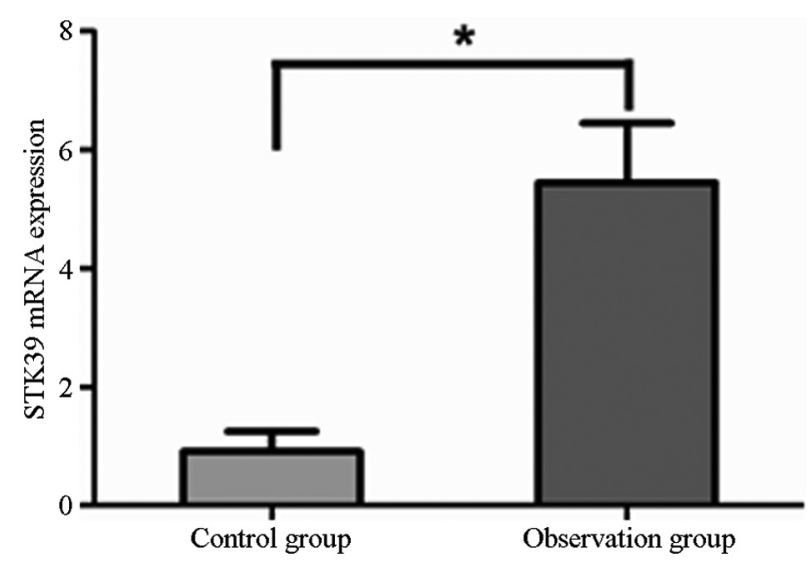

Figure 1. Comparison of STK39 mRNA levels in peripheral blood cells in both groups.

\section{Comparison of STK39 protein level in peripheral blood cells}

In this research, western blotting technique was used to analyze the expression of STK39 protein in peripheral blood cells of both groups; the results are shown in Figure 2A. Under similar GAPDH levels, STK39 protein banding in peripheral blood cells of the observation group was more distinct compared to the control group. The quantitative analysis results are shown in Figure 2B. The observation group has a more marked ratio of STK39 banding gradation/GAPDH banding gradation than the control group, and the difference was of statistical significance $(P<0.05)$.

\section{The analysis of STK39 gene SNP genetic variation}

PCR was conducted to amplify STK39 gene SNP (rs6433027) segment, which was connected to $T$ carrier, and monoclonal ones were taken out for sequencing. The sequencing results are shown in Figure 3. C/T mutation existed in STK39 gene SNP (rs6433027). There were 
three cases of variation in the control group accounting for 10\% (3/30). Whereas, there were 24 cases of variation in the observation group accounting for $57.15 \%(24 / 42)$. The patients of the observation group had significantly higher genetic variation rate of STK39 gene SNP (rs6433027) than the control group, and the difference was of statistical significance $(P<0.05)$. The patients of the observation group were divided into two groups based on the variation of STK39 gene SNP (rs6433027): variation group and wild-type group. The variation group had significantly higher diastolic and systolic blood pressure than the wild-type group, and the difference was statistically significant $(P<0.05)$ (Figure 4).

A

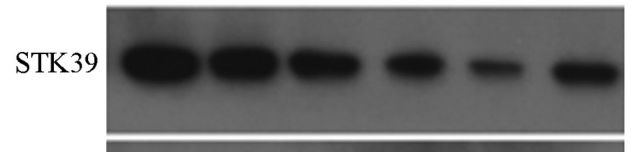

GAPDH

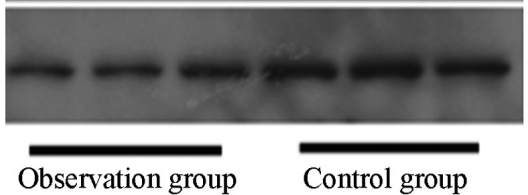

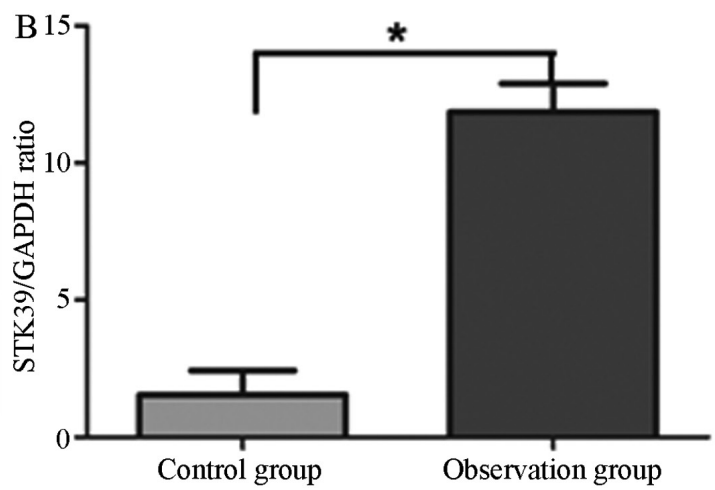

Control group
Observation group

Figure 2. Comparison of STK39 protein level in peripheral blood cells in both groups. A. Results of western blot. B. Quantitative analysis results.

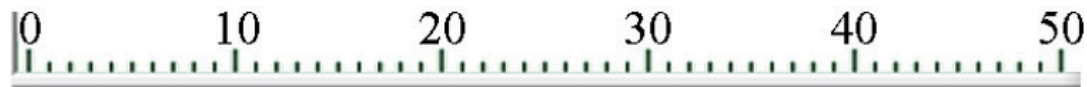

Variation.seq

Wide-type.seq

GTGGAGAACCACTGCAGAGTTTTGRTGAACTATGAACACAATCTGGCTTA GTGGAGAACCACTGCAGAGTTTTGA OTGAACTATGAACACAATCTGGCTTA

Consensus gtggagaaccactgcagagttttga tgaactatgaacacaatctggctta

Figure 3. Analysis of STK39 gene SNP genetic variation.

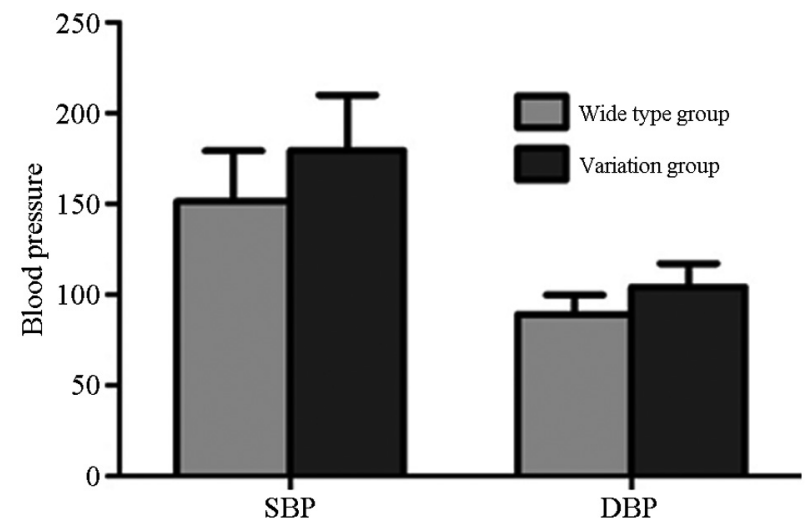

Figure 4. Comparison of blood pressure in patients with different STK39 gene SNP genetic variation. 


\section{Analysis of the relationship between STK39 protein level, genetic variation, and blood pressure}

Linear correlation analysis indicated that STK39 protein level of peripheral blood was positively associated with the diastolic and systolic blood pressure $(r=0.577, P<0.05 ; r=0.394$,

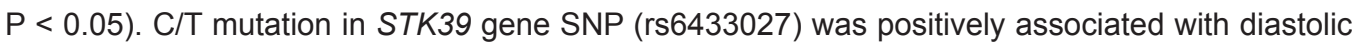
and systolic blood pressure $(r=1.064, P<0.05 ; r=0.796, P<0.05)$.

\section{DISCUSSION}

Hypertension can be classified as primary (hereafter referred to as hypertension) and secondary hypertension, with more than $95 \%$ of cases categorized as primary hypertension. Hypertension results from a complex interaction of genes and environmental factors. The environmental factors lead to varied clinical types when affecting different genetic background, while genetic factors play a vital role in the occurrence and development of primary hypertension. It is considered that minor gene mode functions in the genetic mechanism of primary hypertension, i.e., most risk alleles from many loci interact with each other, reaching the critical threshold of disease, and they co-decide the genetic susceptibility of hypertension (Li and Liu, 2008; Brenner and Chung, 2011). The determination of hypertension susceptibility genes contributes to defining the pathophysiology, and provides theoretical basis for preventing and treating hypertension. The current strategies for the genetic study of hypertension are candidate genes and whole genome scanning. In the GWAS, many new genes relating to primary hypertension are found, such as ATP2B1, CYP17A1, PLEKHA7, SH2B3, MTHFR, CASZ1, ULK4, HFE, EBF1, and STK39 (Germain et al., 2013; Xi et al., 2014).

STK39 was determined in Amish individuals by GWAS. However, its expression is not found in British Caucasian, which suggests the possible reason for the ethnic variation of primary hypertension (Cunnington et al., 2009). Wang et al. (2009) reported the first GWAS meta-analysis of hypertension. They first conducted an analysis on 542 subjects, and then combined the data of six flocks of people ( $\mathrm{N}=7125)$ and conducted meta-analysis, and found that STK39 gene is significantly associated with blood pressure level. Chen et al. (2012) found two common genetic mutation of STK39, rs3754777 and rs6433027, which are the susceptibility loci of hypertension of Han Chinese males, but are not related to female hypertension. Besides, the study also indicates that $\mathrm{T}$ allele of rs6433027 presents strong epistasis in A allele of rs3754777. The study results manifest that STK39 is an independent risk factor of male hypertension, and its SNPs can interact with each other and control blood pressure.

Our control study analyzed the expression of STK39 in peripheral blood of male primary hypertension patients and male healthy individuals. STK39 mRNA level in peripheral blood cells of hypertension patients is remarkably higher compared to healthy individuals; the result was further verified on protein level with ELISA, and STK39 protein level of peripheral blood was found to be higher in hypertension patients than in healthy individuals. It demonstrates that primary hypertension patients have abnormal expression of STK39 mRNA and protein levels, so they possibly participate in the occurrence and development of hypertension.

The report also indicated that genetic variation may exist in or near STK39 in hypertension patients. It is related to the diastolic pressure and systolic pressure of the patient (Xi et al., 2013). We amplified STK39 gene SNP (rs6433027) segment and analyzed the genetic variation of the 
segment, and investigated the association between the variations and the blood pressure of hypertension patients. The study results manifest that C/T genetic mutation exists in STK39 gene SNP (rs6433027), and correlation analysis indicates that $\mathrm{C} / \mathrm{T}$ mutation is positively associated with diastolic pressure and systolic pressure. These results further verify previous study results, providing theoretical basis for figuring out the pathogenesis of genetic factors of hypertension.

Sampling size considered in this study is small. It possibly requires the application of diverse samples, centers, and ethnic groups. Together, this study offers a basis for understanding the pathogenesis of genetic factors of hypertension. It is believed that in the near future, the development of molecular genetics and molecular biology will help control the incidence of primary hypertension.

\section{Conflicts of interest}

The authors declare no conflict of interest.

\section{REFERENCES}

Brenner L and Chung WK (2011). Clinical and molecular genetic features of hereditary pulmonary arterial hypertension. Compr. Physiol. 1: 1721-1728.

Chen LY, Zhao WH, Tian W, Guo J, et al. (2012). STK39 is an independent risk factor for male hypertension in Han Chinese. Int. J. Cardiol. 154: 122-127.

Cunnington MS, Kay C, Avery PJ, Mayosi BM, et al. (2009). STK39 polymorphisms and blood pressure: an association study in British Caucasians and assessment of cis-acting influences on gene expression. BMC Med. Genet. 10: 135.

Duarte JD, Lobmeyer MT, Wang Z, Chapman AB, et al. (2010). Lack of association between polymorphisms in STK39, a putative thiazide response gene, and blood pressure response to hydrochlorothiazide. Pharmacogenet. Genomics 20: 516-519.

Germain M, Eyries M, Montani D, Poirier O, et al. (2013). Genome-wide association analysis identifies a susceptibility locus for pulmonary arterial hypertension. Nat. Genet. 45: 518-521.

Kato N, Takeuchi F, Tabara Y, Kelly TN, et al. (2011). Meta-analysis of genome-wide association studies identifies common variants associated with blood pressure variation in east Asians. Nat. Genet. 43: 531-538.

Keamey PM, Whelton M, Reynolds K, Muntner P, et al. (2005). Global burden of hypertension: analysis of world wide data. Lancet 365: 217-223.

Levy D, Ehret GB, Rice K, Verwoert GC, et al. (2009). Genome-wide association study of blood pressure and hypertension. Nat. Genet. 41: 677-687.

Li YM and Liu J (2008). Development in study of effect of pulse pressure and pulse pressure index on target organ damage in essential hypertensive patients. Adv. Cardiovasc. Dis. 19: 307-310.

Pan S, Naruse $\mathrm{H}$ and Nakayama T (2015). Progress and issues of the genome-wide association study for hypertension. Curr. Med. Chem. 22: 1016-1029.

Pearson TA and Manolio TA (2008). How to interpret a genome-wide association study. JAMA 299: 1335-1344.

Su XL (2010). Research progress in genome-wide association study of susceptibility genes of hypertension. Natl. Med. J. China 90: 3022-3024.

Wang Y, O'Connell JR, McArdle PF, Wade JB, et al. (2009). Whole-genome association study identifies STK39 as a hypertension susceptibility gene. Proc. Natl. Acad. Sci. U. S. A. 106: 226-231.

Xi B, Chen M, Chandak GR, Shen Y, et al. (2013). STK39 polymorphism is associated with essential hypertension: a systematic review and meta-analysis. PLoS One 8: e59584.

Xi B, Shen Y, Zhao X, Chandak GR, et al. (2014). Association of common variants in/near six genes (ATP2B1, CSK, MTHFR, CYP17A1, STK39 and FGF5) with blood pressure/hypertension risk in Chinese children. J. Hum. Hypertens. 28: 32-36.

Xu J, Ji LD, Zhang LN, Dong CZ, et al. (2013). Lack of association between STK39 and hypertension in the Chinese population. J. Hum. Hypertens. 27: 294-297. 